\title{
O SELÊNIO NO MEIO AMBIENTE
}

\author{
Tércia G. Seixas ${ }^{1,2 *}$ \& Helena do A. Kehrig ${ }^{2}$
}

${ }^{1}$ Departamento de Química, PUC-Rio, Rua Marquês de São Vicente, 225 - Gávea, CEP: 22453-900, Rio de Janeiro, RJ, Brasil.

${ }^{2}$ Laboratório de Radioisótopos Eduardo Penna Franca, IBCCF-UFRJ, Ilha do Fundão, CEP: 21941-902, Rio de Janeiro, RJ, Brasil.

*e-mail: tercia@rdc.puc-rio.br

\section{RESUMO}

O selênio é conhecido como um elemento de grande importância fisiológica e ecotoxicológica, uma vez que é um micronutriente essencial para a maioria dos organismos, mas também torna-se tóxico em concentrações elevadas. Por esta razão, há um grande interesse em se entender o comportamento deste elemento no meio ambiente. Nesta revisão, alguns aspectos importantes com relação a este elemento são apresentados.

Palavras-chave: Selênio; papel fisiológico; deficiência; efeito protetor; toxicidade.

\begin{abstract}
SELENIUM IN THE ENVIRONMENT. Selenium is known as an element of great physiological and ecotoxicological importance due to it is an essential micronutrient for some organisms, but it is also toxic at elevated concentrations. For this reason, there is an increasing interest in understanding the behavior of selenium in the environment. In this review, some important aspects related this element is described.
\end{abstract}

Key-words: Selenium; physiological role; deficiency; protector effect; toxicity.

\section{INTRODUÇÃO}

O selênio (Se) é conhecido como um micronutriente essencial para a maioria dos organismos (Chatterjee et al. 2001), porém, este elemento possui uma ambigüidade biológica em que: (1) em concentrações traço é necessário para o crescimento e desenvolvimento normal do organismo; (2) em concentrações moderadas pode ser armazenado e mantém as funções homeostáticas e (3) em concentrações elevadas pode resultar em efeitos tóxicos (Hamilton 2004). Dentre os elementos essenciais, o selênio é considerado o mais tóxico uma vez que a diferença existente entre a dose essencial e a tóxica é muito pequena (Chapman 1999). As crescentes atividades antropogênicas têm aumentado a liberação e o emprego do selênio de suas fontes naturais (rochas e solos), tornando-o disponível principalmente para o meio ambiente aquático e consequentemente para o homem; uma vez que a principal via de exposição tanto do homem quanto dos organismos aquáticos ao selênio é através da dieta alimentar. Há várias décadas o "quebra-cabeça" chamado selênio vem sendo aos poucos montado tanto no campo biológico, quanto no campo ecotoxicológico. A cada estudo são atribuídas mais funções biológicas importantes a este elemento traço. A função protetora e antagônica que este elemento desempenha contra a ação tóxica de certos metais $(\mathrm{Hg}, \mathrm{Cd}, \mathrm{Pb})$ e metalóides (As) é uma delas. Porém, seu mecanismo é complexo e ainda não foi totalmente elucidado. Somente para o mercúrio $(\mathrm{Hg})$ esta interação parece já estar um pouco esclarecida. Estudos realizados com mamíferos marinhos (Wagemann et al. 1998, 2000) mostraram, através de um mecanismo hipotético, que o selênio através das selenoproteínas proporciona a demetilação do metilmercúrio $(\mathrm{MeHg})$ por meio da formação de grânulos inertes de seleneto mercúrico $(\mathrm{HgSe})$ no fígado desses organismos. A seguir serão apresentados alguns pontos relevantes a respeito deste elemento de grande importância fisiológica e ecotoxicológica.

\section{O SELÊNIO E SEUS COMPOSTOS NO AMBIENTE}

O selênio é um metalóide que foi isolado e identificado em 1817 pelo químico sueco Jöns Jacob Berzelius (1779-1848) quando este observou um depósito vermelho sobre as paredes de uma câmara de chumbo usada para produzir ácido sulfúrico (Foster \& Sumar 1997, Barceloux 1999). Este elemento pertence ao grupo 16 da tabela periódica, e está localizado entre o enxofre e o telúrio. Ambos 
possuem propriedades químicas e físicas semelhantes, sendo em maior extensão com o enxofre e em menor extensão com o telúrio (OMS 1987, Jonnalagadda \& Rao 1993). Algumas propriedades químicas e físicas do selênio são resumidas na Tabela I.

Tabela I. Algumas propriedades físicas e químicas do selênio.

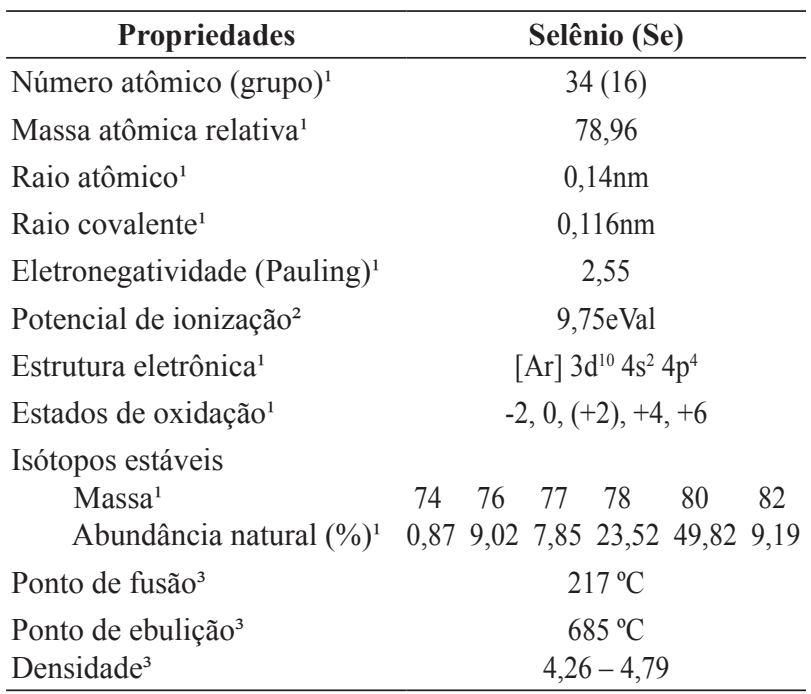

(Referências: 1. OMS 1987; 2. Shibata et al. 1992; 3. Eisler 1985).
O selênio é um elemento que existe naturalmente em quatro estados de oxidação (-II, $0,+\mathrm{IV}$ e +VI) onde, somente o seu estado +2 não é encontrado no ambiente (OMS 1987) e também, em duas formas químicas (inorgânica e orgânica). Alguns de seus compostos são voláteis, o que facilita sua distribuição no ambiente (OMS 1987) (Tabela II).

A toxicidade e a biodisponibilidade dos compostos de selênio vai depender em grande parte da sua forma química. Por exemplo, o selenato-SeVI $\left(\mathrm{SeO}_{4}{ }^{2-}\right)$ e o selenito-SeIV $\left(\mathrm{SeO}_{3}^{2-}\right)$ são espécies altamente solúveis em água e são conhecidas por serem tóxicas para sistemas biológicos em concentrações relativamente baixas. Enquanto, o selênio elementar $\left(\mathrm{Se}^{0}\right)$ é uma espécie insolúvel em água e não apresenta nenhuma toxicidade para os sistemas biológicos. Os selenetos $\left(\mathrm{Se}^{-2}\right)$ são espécies altamente tóxicas e reativas que são rapidamente oxidadas a $\mathrm{Se}^{0}$ (Wachowicz et al. 2001). Porém, na forma orgânica tornam-se as espécies mais biodisponíveis para os organismos. Os compostos de selênio inorgânico podem ser transformados em compostos de selênio organometálicos através da

Tabela II. Formas químicas do selênio no ambiente.

\begin{tabular}{|c|c|c|}
\hline Nome & Fórmula & Características \\
\hline Selenetos (-2) & $\mathrm{Se}^{2-}$ & $\begin{array}{l}\text { É encontrado em ambientes redutores, ex. solos, sedimen- } \\
\text { tos. Forma complexos metálicos e é altamente imóvel. }\end{array}$ \\
\hline Dimetilseleneto & $\left(\mathrm{CH}_{3}\right)_{2} \mathrm{Se}$ & Gás formado pelas bactérias e fungos do solo. \\
\hline Dimetildiseleneto & $\left(\mathrm{CH}_{3}\right)_{2} \mathrm{Se}_{2}$ & Gás formado pelas plantas. \\
\hline $\begin{array}{l}\text { Dimetilselenona/ metil } \\
\text { Metilseleneto (DMSe) }\end{array}$ & $\left(\mathrm{CH}_{3}\right)_{2} \mathrm{SeO}_{2}$ & $\begin{array}{l}\text { Metabólito volátil, possivelmente formado como um } \\
\text { intermediário antes da redução a DMSe. }\end{array}$ \\
\hline Seleneto de hidrogênio & $\mathrm{H}_{2} \mathrm{Se}$ & Gás, instável em ar úmido; decompõe-se a $\mathrm{Se}^{0}$ em água. \\
\hline Selênio elementar (0) & $\mathrm{Se}^{0}$ & Estável em ambientes redutores. \\
\hline Selenito $(+4)$ & $\mathrm{SeO}_{3}^{2-}$ & $\begin{array}{l}\text { Forma solúvel, comum em condições suavemente oxi- } \\
\text { dantes, ex.: solos e partículas de ar. }\end{array}$ \\
\hline Trimetilselenônio & $\left(\mathrm{CH}_{3}\right)_{3} \mathrm{Se}^{+}$ & $\begin{array}{l}\text { É um importante metabólito urinário da dieta de Se e, } \\
\text { torna-se rapidamente não-disponível devido sua fixação } \\
\text { pelas plantas ou volatilização. }\end{array}$ \\
\hline Ác. Selenoso & $\mathrm{H}_{2} \mathrm{SeO}_{3}$ & $\begin{array}{l}\text { É protonado em condições ácido/neutro. É facilmente re- } \\
\text { duzido a } \mathrm{Se}^{\mathrm{o}} \text { pelo ác. ascórbico (vitamina } \mathrm{C} \text { ), ou dióxido de } \\
\text { enxofre em ambientes acidificados por microorganismos. }\end{array}$ \\
\hline Dióxido de selênio & $\mathrm{SeO}_{2}$ & $\begin{array}{l}\text { Gás formado como sub-produto da queima de combustí- } \\
\text { veis fósseis (temperatura de sublimação, } 300{ }^{\circ} \mathrm{C} \text { ). }\end{array}$ \\
\hline & $\begin{array}{l}\mathrm{HSeO}_{3}^{-} \\
\mathrm{SeO}_{4}^{2-}\end{array}$ & Comum em solos. \\
\hline Selenato $(+6)$ & $\mathrm{H}_{2} \mathrm{SeO}_{4}$ & $\begin{array}{l}\text { É estável em ambientes oxidados, é muito móvel em so- } \\
\text { los, estando prontamente disponível para as plantas. } \\
\text { Lentamente convertido às formas mais reduzidas, não é } \\
\text { tão fortemente absorvido como Se (IV). Ácido forte que } \\
\text { não é protonado no pH de águas naturais. } \\
\text { Comum em solos. }\end{array}$ \\
\hline & $\mathrm{HSeO}_{4}^{-}$ & \\
\hline
\end{tabular}


atividade bacteriana (Olivas et al. 1994). Deste modo, o selênio se comporta como um elemento ambíguo em sistemas biológicos, uma vez que ora a espécie pode ser considerada como essencial ou pode ser considerada tóxica quando a dose é superior àquela requerida nutricionalmente (Olivas et al. 1994).

Os compostos de selênio entram no meio ambiente por intermédio de fontes naturais (processos geofísicos e biológicos) e fontes antropogênicas (processos industriais e agricultura). As fontes naturais são, provavelmente, as responsáveis pela presença de selênio no ambiente, enquanto as antropogênicas são responsáveis pela redistribuição deste no ambiente (OMS 1987). Isto ocorre através da liberação de selênio das fontes geológicas e pela disponibilização deste para os organismos dos ecossistemas terrestre e aquático (Hamilton 2004). A atmosfera representa a maior fonte natural de selênio para a superfície terrestre, via deposição seca e úmida enquanto, o ambiente marinho é pressuposto ser a maior fonte de selênio para a atmosfera. Como fontes antropogênicas de selênio para o ambiente podem-se citar: as indústrias de refino de cobre, produtoras de vidro e de equipamentos eletrônicos; águas de drenagem; efluentes; plantas de beneficiamento de carvão; refinarias; uso em fertilizantes; mineração de fosfatos e outros metais (Eisler 1985).

Segundo Kölbl (1995), o selênio está presente na crosta terrestre, nos solos, nas águas de rios e oceanos, nos sedimentos e nas amostras biológicas em concentrações que variam de $4 \cdot 10^{-5} \mathrm{mg} \cdot \mathrm{Kg}^{-1}$ a vários milhares de mg. $\mathrm{Kg}^{-1}$ (Tabela III).

O conhecimento sobre os compostos de selênio no ecossistema aquático é muito limitado devido à maioria dos trabalhos analíticos neste campo serem feitos para selênio total ou para espécies de selênio inorgânico. Somente poucos compostos orgânicos de selênio foram identificados e determinados em amostras marinhas (Kölbl 1995) (Tabela IV). Vários outros compostos orgânicos de selênio, tais como selenocarboidratos e selenonucleotídeos, podem ocorrer no ambiente marinho, mas ainda não foram identificados.

Maier (1987) observou que mais de 50\% do selênio total encontrado nos sedimentos e mais de $91 \%$ do encontrado nos organismos marinhos, está presente na forma orgânica, concluindo então, que esta ligação orgânica do selênio é parte essencial do ciclo natural do selênio, o que sugere, portanto, o envolvimento do selênio na atividade biológica.
Tabela III. Concentração de selênio total em diferentes matrizes.

\begin{tabular}{ll}
\hline Material & Se $\left(\mu \mathrm{g} . \mathrm{g}^{-1}\right)$ \\
\hline $\begin{array}{l}\text { Abiótico: } \\
\text { Crosta terrestre }\end{array}$ & \\
Solos & $0,05-0,09$ \\
Não-seleníferos & \\
Seleníferos & \\
Água de rio $^{2}$ & \\
& $<0,1-2,0$ \\
Água do mar (Pacifico Norte) $_{\text {Superfície }^{3}}$ & $1-1200$ \\
$6000 \mathrm{~m}^{3}$ & $1 \times 10^{-4}-4 \times 10^{-4}$ \\
& \\
&
\end{tabular}

Sedimentos marinhos

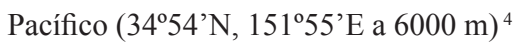

Concreções marinhas ferro-manganês ${ }^{5}$

$0,05-0,4^{\mathrm{a}}$ $0,02-1,2^{\mathrm{a}}$

\section{Biótico:}

Fitoplâncton marinho ${ }^{6}$

$0,5-2,7^{\mathrm{a}}$

Fitoplâncton (Baía de Guanabara, Brasil) ${ }^{7}$

Zooplâncton (Baía de São Francisco, USA) ${ }^{8}$

$0,02-0,05^{\mathrm{a}}$

$1,0-6,1^{\text {a }}$

Zooplâncton (Baía de Guanabara, Brasil) ${ }^{7}$

$0,03-0,07^{\mathrm{a}}$

\section{Mamiferos Marinhos}

Músculo9

$0,1-0,4$

Fígado 9

Fígado $^{10}$

$0,6-74,9$

$\operatorname{Rim}^{10}$

$7,0-8,8^{a}$

Peixe marinho

Músculo $^{6}$

$0,9-4,0$

Fígado $^{6}$

$1,4-28,3^{\mathrm{a}}$

\section{Peixes}

Músculo (Baía de Guanabara, Brasil) ${ }^{11}$

Músculo (Baía de Guanabara, Brasil) 7

Fígado (Baía de Guanabara, Brasil) ${ }^{11}$

Fígado (Baía de Guanabara, Brasil) ${ }^{7}$

$0,07-0,3$

$0,05-4,0$

$0,4-13,7$

$1,6-45,1$

Mexilhão

Tecidos moles (Baía de Guanabara, Brasil) ${ }^{11}$

$0,1-0,3$

Tecidos moles (Baía de Sepetiba, Brasil) ${ }^{12}$

$3,0-3,6^{\mathrm{a}}$

Ostra

Tecidos moles (Baía de Sepetiba, Brasil) ${ }^{12} \quad 1,5-5,1^{\mathrm{a}}$

Vôngole

Tecidos moles (Baía de Sepetiba, Brasil) ${ }^{12} \quad 0,88-0,90^{\mathrm{a}}$

Aves Marinhas

Fígado $^{13} \quad 6,9-13,6^{\mathrm{a}}$

$\operatorname{Rim}^{13} \quad 10,2-22,0^{a}$

Pena $^{13}$

$0,7-1,4^{\text {a }}$

a Concentrações expressas em massa seca. (Referências: 1. McNeal \& Balistrieri 1989; 2. Maier et al. 1987; 3. Aono et al. 1991; 4. Tamari 1979; 5. Takematsu et al. 1990; 6. Liu et al. 1987; 7. Kehrig et al. 2007b; 8. Purkerson et al. 2003; 9. Kehrig et al. 2004; 10. Seixas et al. 2007b; 11. Seixas et al. 2007a; 12. Kehrig et al. 2006; 13. Kehrig et al. 2007a). 
Tabela IV. Compostos orgânicos de selênio identificados no ambiente aquático.

\begin{tabular}{|c|c|}
\hline Composto & Amostra \\
\hline $\begin{array}{l}\text { Dimetil seleneto } \\
\text { Dimetil diseleneto }\end{array}$ & $\begin{array}{l}\text { Atlântico }^{1,2} \\
\text { Parte superior das amostras } \\
\mathrm{H}_{2} \mathrm{O}^{3} \\
\text { Parte superior de solução } \\
\text { cultura p/ algas de rio } 4 \\
\text { Água de lago }\end{array}$ \\
\hline Íon trimetilselenônio & $\begin{array}{l}\text { Solução cultura p/ algas de } \\
\text { rio }^{4} \\
\text { Água de lago }^{5} \\
\text { Lago e lençol d'água }^{6}\end{array}$ \\
\hline $\begin{array}{l}\text { Ácido selenoamino } \\
\text { (ác. Selenocisteico, } \\
\text { Se-metilselenocisteína, sele- } \\
\text { nocistina, selenometionina, } \\
\text { Se-metilselenometionina, } \\
\text { selenóxido de selenometioni- } \\
\text { na, selenohomocistina) }\end{array}$ & $\begin{array}{l}\text { Alga marinha } \\
\text { Fitoplâncton marinho } \\
\text { Ostra marinha }^{9} \\
\text { Água do mar }{ }^{10}\end{array}$ \\
\hline $\begin{array}{l}\text { Selenoproteínas } \\
\text { (proteínas de baixo peso } \\
\text { molecular, contendo } \mathrm{Hg} \text {-Se, } \\
\text { glutationa peroxidase) }\end{array}$ & $\begin{array}{l}\text { Tecidos de mexilhão } \\
\text { Fígado de golfinho }^{12,13} \\
\text { Fígado de atum }^{14}\end{array}$ \\
\hline Selenolipídios & Alga marinha ${ }^{15}$ \\
\hline
\end{tabular}

(Referências: 1. Tanzer \& Heumann 1990; 2. Tanzer \& Heumann 1992; 3. Thompson-Eagle \& Frankenberger 1990; 4. Oyamada et al. 1991; 5. Cooke \& Bruland 1987; 6. Oyamada \& Ishizaki 1986; 7. Bottino et al. 1984; 8. Wrench 1978; 9. Wrench \& Measures 1979; 10. Cutter 1982; 11. Luten et al. 1987; 12. Ping et al. 1986; 13. Matsumoto 199; 14. BraddonGalloway \& Sumpter 1986; 15. Gennity et al. 1984).

Assim, fatores ambientais e biológicos têm uma profunda influência na subseqüente disponibilidade e toxicidade do selênio para os organismos (Amweg et al. 2003).

\section{O CICLO DO SELÊNIO NO SISTEMA AQUÁTICO}

Segundo Pelletier (1985), o ciclo biogeoquímico do selênio no meio ambiente aquático é parcialmente conhecido. Sabe-se, que devido a sua semelhança química com o enxofre, ambos possuem ciclos análogos no meio-ambiente (Besser et al. 1996).

Lemly (1999) sugeriu que três coisas podem acontecer ao selênio quando este entra no ecossistema aquático:

1. Pode ser absorvido ou ingerido pelos organismos (Figura 1);

2. Pode ligar-se ou complexar-se ao material particulado ou à superfície do sedimento (Figura 2);

3. Pode permanecer livre em solução.

Bowie et al. (1998) mostraram em seu estudo que mais de $90 \%$ do selênio total no sistema aquático encontra-se nos sedimentos (Figura 3). Este é ciclado por processos físicos, químicos e biológicos, permanecendo em níveis elevados por anos, mesmo após os lançamentos de selênio terem cessado (Lemly 1999b).

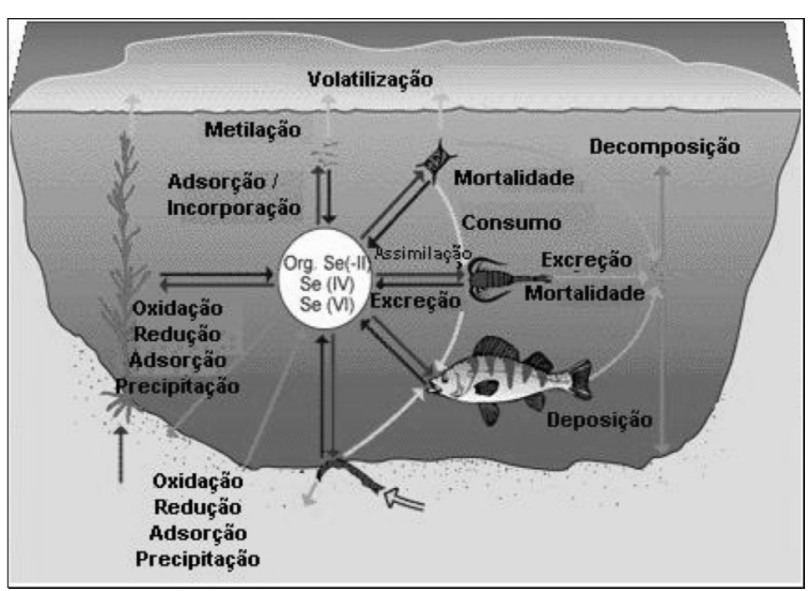

Figura 1. Ciclo biológico do selênio no ambiente aquático (adaptado de Bowie et al. 1998).

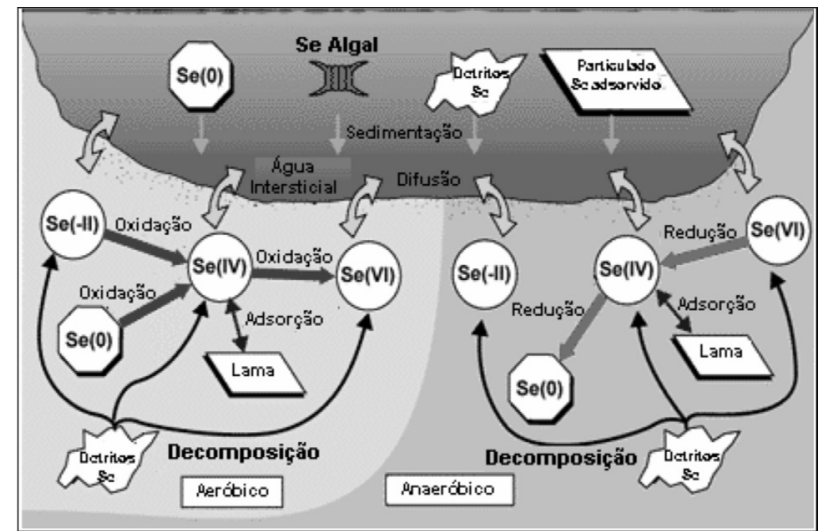

Figura 2. Ciclo do selênio no sedimento (adaptado de Bowie et al. 1998).

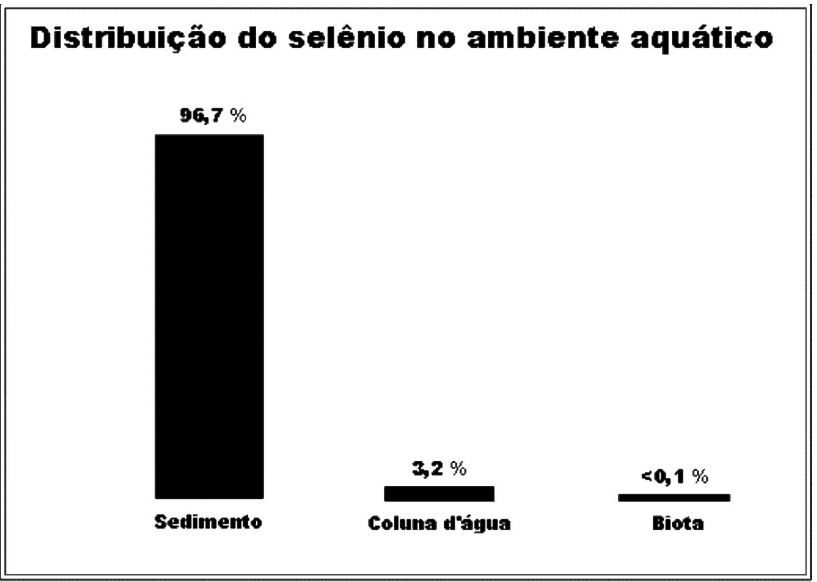

Figura 3. Distribuição do selênio no ambiente aquático (adaptado de Bowie et al. 1998). 


\section{PROCESSOS DE IMOBILIZAÇÃO}

O selênio pode ser removido da coluna d'água por intermédio de processos naturais de redução química e microbiana do selenato a selenito (Figura 1), seguido pela adsorção deste ao particulado. Independente da rota, o selênio, no sedimento, pode ser reduzido através de processos químicos e microbianos, que resultam em suas formas imobilizadas (compostos orgânicos insolúveis, selenetos, selênio elementar e selênio adsorvido). A maioria do selênio, proveniente dos tecidos animais e vegetais, é depositada como detrito e é isolada através de processos de sedimentação (Figura 2). Certas formas orgânicas podem ser liberadas por volatilização, para a atmosfera, através de atividades químicas e microbianas que ocorrem na coluna d'água e sedimentos, ou simplesmente, serem liberadas pelas plantas superiores (Lemly 1999b).

\section{PROCESSOS DE MOBILIZAÇÃO}

O selênio torna-se disponível para a biota através de quatro processos, de oxidação e metilação (Lemly 1999b) (Figura 1).

O primeiro processo ocorre através da oxidação e metilação do selênio inorgânico: as raízes das plantas aquáticas e os microorganismos bentônicos, através da oxidação convertem as formas imobilizadas nas formas solúveis, selenito e selenato; e através da metilação convertem o selênio inorgânico em formas orgânicas que contêm um ou mais radicais metil que, usualmente, resultam numa forma volátil).

O segundo processo é o de bioturbação realizado pelos invertebrados bentônicos com conseqüente oxidação do sedimento.

O terceiro processo érepresentado pela perturbação física e oxidação química, associadas à circulação da água.

E, finalmente no quarto processo, os sedimentos podem ser oxidados pelas plantas fotossintéticas.

Uma vez mobilizado do sedimento, o selênio entra na cadeia alimentar dos sistemas aquáticos através de seus primeiros níveis tróficos, comunidade planctônica, e então é distribuído e acumulado através dos níveis tróficos subseqüentes, podendo então, sofrer os processos de bioconcentração e bioacumulação (Figuras 1 e 2).
Segundo Rand et al. (1995), o processo de bioconcentração é definido como a incorporação do composto por um organismo diretamente do ambiente abiótico resultando numa maior concentração do composto no organismo e, o processo de bioacumulação é definido como a incorporação do composto pelo organismo tanto do meio abiótico quanto biótico (alimento), isto é, o organismo acumula o composto oriundo de todas as fontes.

\section{O SELÊNIO NOS ORGANISMOS}

Os organismos vivos são compostos de uma variedade de elementos essenciais para o desenvolvimento dos mesmos. O selênio faz parte dos 26 elementos essenciais identificados até o momento. Estes consistem dos 11 macronutrientes: carbono, hidrogênio, nitrogênio, oxigênio, fósforo, enxofre, potássio, sódio, cálcio, magnésio e cloro e dos 15 micronutrientes: ferro, iodo, cobre, magnésio, zinco, cobalto (descobertos antes de 1935), molibdênio, selênio, cromo, estanho, vanádio, flúor, silício, níquel e arsênio (descobertos como essenciais no período de 1953 a 1976) (Shibata et al. 1992).

O selênio foi identificado como elemento essencial para os organismos em 1957 por Schwartz \& Foltz. Até então, acreditava-se ser ele apenas um substituto da vitamina $E$, suprindo em vários casos sua deficiência. A confirmação do seu papel como elemento essencial independente da vitamina $E$ foi evidenciada a partir de experiências de Thompson \& Scott (1969) com aves. Eles mostraram que animais cuja dieta continha menos de $5 \mu \mathrm{g} . \mathrm{g}^{-1}$ de selênio apresentavam baixo crescimento ou índice superior de mortalidade, ainda que com suprimento adequado de vitamina E. Descobrindo-se assim, o importante papel fisiológico do selênio.

Desde a descoberta de Schwartz \& Foltz em 1957, muitos trabalhos foram realizados para se elucidar o metabolismo e o papel do selênio em organismos vivos, particularmente em ambientes terrestres (NAS 1976, OMS 1987).

Estudosindicamque o selênio exerce suas principais funções biológicas nos mamíferos sob a forma de selenoproteínas. Estas são proteínas que incorporam selênio como selenocisteína ( $21^{\circ}$ aminoácido) e desempenham importantes papéis fisiológicos. Onze selenoproteínas já foram identificadas: glutationa peroxidase (celular ou clássica); glutationa peroxidase 
(plasmática ou extracelular); glutationa peroxidase hidroperóxido fosfolipídica; glutationa peroxidase gastrointestinal; selenoproteína $\mathrm{P}$; iodotironina deiodinase tipos I, II e III; selenoproteína W; tioredoxina redutase e selenofosfato sintetase. Dentre estas, tanto a glutationa peroxidase celular quanto a plasmática são os parâmetros funcionais utilizados na determinação do status de selênio no organismo. Os níveis de atividade destas enzimas no fígado e no plasma são indicativos de suprimento de selênio para o organismo. As glutationas peroxidase catalisam a redução dos peróxidos que podem causar danos celulares. Enquanto a tioredoxina redutase reduz a eficiência de vários processos bioquímicos defendendo o organismo contra o stress oxidativo. Aselenoproteína Pdesempenha um papel de antioxidante. Papel este que pode ser desempenhado também, pela selenoproteína W que está envolvida no metabolismo muscular. As tireóides deiodinase (iodotironina deiodinase) estão envolvidas na formação e regulação dos hormônios tireoideanos. A selenofosfato sintetase é uma enzima requerida para a incorporação da selenocisteína pelas selenoproteínas. Em adição, uma outra selenoproteína (glutationa peroxidase hidroperóxido fosfolipídica) encontrada na cápsula mitocondrial do esperma é vital para a integridade do flagelo do esperma (Holben \& Smith 1999).

O selênio possui também, um efeito sinergético com a vitamina E. Ele exerce seu efeito através da enzima glutationa peroxidase. Isto é, os nutrientes complementam-se em suas atividades e protegem as membranas biológicas contra a oxidação lipídica (OMS 1987). Enquanto o tocoferol inibe a formação de peróxidos, agindo como antioxidante intracelular, impedindo o dano oxidativo de ácidos graxos polinsaturados em membranas biológicas (terminando as reações em cadeia de peróxidos lipídicos) (OMS 1987), o selênio degrada os peróxidos já existentes (Oberback \& Hartfiel 1988 apud Watanabe et al. 1997), isto é, catalisa a destruição do peróxido de hidrogênio ou a decomposição dos hidroperóxidos lipídicos, fazendo interromper a reação peroxidativa em cadeia dos radicais livres (OMS 1987).

O selênio tem uma meia-vida biológica relativamente curta. Estudos utilizando ${ }^{75} \mathrm{Se}$ indicam que sua meia-vida biológica em várias espécies de organismos aquáticos varia de 13 a 81 dias: 28 dias para carpas
(Sato et al. 1980), 37 dias para o crustáceo marinho Meganyetiphanes norvegica (Fowler \& Benayoun 1976), 63 a 81 dias para o mexilhão marinho Mytilus galloprovincialis (Fowler \& Benayoun 1976), 58 a 60 dias para o camarão marinho Lysmata caudata (Fowler \& Benayoun 1976) e, como revisado por Stadtman (1974, 1977), 13 dias para lebistes, 27 dias para enguias e 28 dias para sanguessuga.

Estudos vêm sugerindo, que o selênio pode exercer uma função protetora contra a ação tóxica de metais pesados como o mercúrio e cádmio (OMS 1987, Cuvin \& Furness 1988, Burger et al. 2001).

O selênio é um micronutriente crítico, pois, por ser constituinte de várias enzimas, não só sua toxicidade, mas também sua deficiência vêm preocupando estudiosos de todo o mundo (Eisler 2000). Sendo, portanto, um elemento de grande importância fisiológica e toxicológica, daí a importância de seu estudo.

\section{DEFICIENNCIA E EFEITO PROTETOR}

Segundo Eisler (2000), a deficiência de selênio não é tão documentada quanto sua toxicidade, mas, é igualmente significante. Tem sido relatado que uma ingestão suficiente de selênio é necessária para promover o crescimento e a prevenção de doenças em animais e no homem.

Em animais, ficou provado que sua deficiência causou o retardamento do crescimento e a morte em salmões (Poston et al. 1976 apud Watanabe et al. 1997), necrose do fígado em ratos e outras espécies (Underwood 1977 apud Vidal 1984), diátese exudativa em trutas (Bell et al. 1985 apud Watanabe et al. 1997) e aves (Underwood 1977 apud Vidal 1984), fibrose pancreática em aves domésticas (Underwood 1977 apud Vidal 1984), distrofia muscular (doença do músculo branco "white muscle disease") em salmões (Poston et al. 1976 apud Watanabe 1997), cordeiros e bezerros (Underwood 1977 apud Vidal 1984) e hepatose dietética em porcos (Underwood 1977 apud Vidal 1984). Em geral, o requerimento nutricional para animais via dieta está em níveis de 0,1 a $0,5 \mu \mathrm{g} \cdot \mathrm{g}^{-1}$ (Ohlendorf 1999). E, segundo Watanabe et al. (1997) para os peixes, este varia de 0,15 a $0,5 \mu \mathrm{g}$ de Se por $\mathrm{g}$ de dieta em peso seco.

A diátese exudativa se caracteriza por edemas no corpo do animal com aparecimento posterior de 
hemorragia subcutânea. Ocorre maior acumulação de fluido sob a pele do peito e do abdômen, ocorrendo uma coloração azul-esverdeada, que se deve a um aumento da permeabilidade dos vasos capilares. Este problema pode ser prevenido tanto pelo administração de selênio quanto pela de vitamina E. A fibrose pancreática implica em atrofia do pâncreas que pode ser regenerado após administração de selênio na dieta. A distrofia muscular nutricional - DMN (ou doença do músculo branco) é uma doença degenerativa dos músculos que pode ser diagnosticada por exame histológico dos tecidos afetados. A hepatose dietética causa lesões no fígado e edemas subcutâneos e é associada a uma diminuição acentuada de selênio no fígado do animal (Vidal 1984).

No homem, alguns estudos já foram feitos nesse campo. Sua deficiência pode contribuir para a incidência da síndrome da deficiência de selênio, ou doença de Keshan (KSD) (Yang et al. 1984 apud Jonnalagadda \& Rao 1993) e da doença de KaschinBeck (KBD) (Sokoloff 1985 apud Jonnalagadda \& Rao 1993). A doença de Keshan é uma doença cardiovascular que afeta principalmente as crianças e mulheres jovens (Chen et al. 1980). Esta doença é endêmica em áreas da China onde ocorre à deficiência de selênio. A incidência das formas aguda e sub-aguda desta doença, nestas áreas, é diminuída drasticamente com a suplementação de selênio na dieta. Entretanto, casos crônicos da doença aparecem após a suplementação com quantidades adequadas de selênio. Isto indica que a deficiência de selênio é mais uma pré-disposição do que a principal causa desta doença (Xu et al. 1997). A doença de Kashin-Beck é uma osteoartropatia endêmica observada em crianças na China, Rússia e Coréia. Kashin foi quem primeiro descreveu esta doença observada na área de Bajkal, na Rússia em 1848. Posteriorment, Beck reportou casos semelhantes em 1906 (Allander 1994).

Estudos indicam que a administração de selênio reduz além dos riscos de doenças cardíacas, os riscos de câncer (Kölbl 1995, Barceloux 1999).

Na literatura, já está clara a função protetora, antagônica, desempenhada pelo selênio contra a ação tóxica dos elementos traço, principalmente do mercúrio, cádmio e arsênio em organismos marinhos (EPA 1998), sobretudo nos mamíferos marinhos, mesmo sob condições normais de exposição (Pal- misano et al. 1995, Dietz et al. 2000, Cardellicchio et al. 2002, Chen et al. 2002). O exato modo da interação entre o selênio com os metais, principalmente os de transição (Sasakura \& Suzuki 1998) e metalóides (Francesconi et al. 1999) é complexo e ainda não está totalmente bem esclarecido (Eisler 1985). Somente os estudos a nível celular vêm indicando que o selênio pode interagir com os elementos traço, mesmo em baixas doses, porém a sua forma química e o seu estado de oxidação são importantes e cruciais (Feroci et al. 1997). Alguns estudos que mostraram a interação, função protetora, do selênio com o mercúrio: em algas, camarões, caranguejos, ostras, peixes (Eisler 1985) e mamíferos (Dietz et al. 2000, Wagemann et al. 2000, Cardellicchio et al. 2002, Chen et al. 2002, Endo et al. 2002). Esse efeito é devido à existência de uma interação entre o mercúrio e as selenoproteínas, que influi tanto no metabolismo quanto no efeito tóxico do metilmercúrio nos organismos marinhos (Schultz et al. 1994), demetilando o metilmercúrio e formando os grânulos inertes de $\mathrm{HgSe}$, que se depositam principalmente no fígado e rins dos mamíferos (Endo et al. 2002). Conseqüentemente, a toxicidade do metilmercúrio tende a diminuir (Schultz et al. 1994). A biota aquática, especialmente os mamíferos marinhos, apresenta uma significante correlação entre as concentrações molares de $\mathrm{Hg}$ e de Se no tecido muscular e no fígado (Palmisano et al. 1995, Dietz et al. 2000, Kehrig et al. 2004 a, b). Entretanto, certas espécies de organismos marinhos, tais como tubarões australianos, crustáceos e moluscos, não apresentam uma correlação significativa de $\mathrm{Hg}$ e Se (Barghigiani et al. 1991). A maioria das amostras de moluscos, crustáceos, peixes e pássaros, provenientes da Groenlândia, apresentaram uma concentração molar de Se excedente à do $\mathrm{Hg}$ (Dietz et al. 2000). No primeiro estudo realizado na região costeira brasileira, na Baía de Guanabara verificou-se que os peixes (corvina e tainha) e o golfinho (Sotalia guianensis) apresentaram boas correlações entre selênio e mercúrio, tanto no fígado quanto no tecido muscular, entretanto esta correlação não foi observada nos tecidos moles do mexilhão (Kehrig et al. $2004 \mathrm{a}, \mathrm{b})$.

Observações similares com relação à proteção que o selênio exerce contra a ação tóxica de metais e metalóides, também foram feitas para cobre em 
algas marinhas; cádmio em moluscos univalves de água doce, caranguejos marinhos, peixes de água doce; e arsênio em peixes marinhos e de água doce (Eisler 1985). Nem todos os testes foram conclusivos, como por exemplo, estudos com algumas espécies de peixes de água doce não demonstraram um antagonismo significante do selênio contra o mercúrio ou cádmio. Mas, estes foram conclusivos para os mamíferos (Eisler 1985).

O selênio e o arsênio são antagonistas em várias espécies de animais como, por exemplo, em ratos, cachorros, gados e aves domésticas (Eisler 1985). As concentrações de arsênio nos tecidos da biota marinha são mais elevadas nos lipídeos, no fígado e no tecido muscular e estas variam de acordo com a idade do organismo, localização geográfica e proximidade de fontes antropogênicas (Eisler 1985, Kubota et al. 2002). Os organismos marinhos acumulam arsênio, assim como o selênio, direto da água do mar ou via dieta alimentar. E, a grande maioria de arsênio presente nos organismos marinhos está na forma de organoarsênicos como, arsenolipídeos, arsenoaçúcares, assim como outras formas organoarsênicas (Eisler 1985). As algas constituem uma importante fonte de organoarsênico para a teia trófica aquática, uma vez que acumulam altas concentrações de arsênio inorgânico e transformando-os em arsênio metilado que posteriormente são transferidos ao longo da cadeia alimentar (Eisler 1985). Recentemente foi sugerido que ocorre a redução da toxicidade do arsênio e do selênio quando estes metalóides são administrados simultaneamente, formando o composto de arsênio-selênio na bílis de coelhos (Gailer et al. 2000).

Com relação ao cádmio, este é acumulado pelos organismos marinhos direto do meio ambiente $\mathrm{e}$ esta acumulação varia de tecido para tecido. Assim como o mercúrio, o cádmio também interage com as selenoproteínas do plasma sanguíneo, formando o complexo (Cd-Se) na razão equimolar, fazendo com que a sua toxicidade diminua (Sasakura $\&$ Suzuki 1998).

\section{TOXICIDADE}

A toxicidade do selênio é bem documentada e foi revisada sob vários pontos de vista, tais como o de um toxicologista marinho (Saiki 1986), toxicologistas da vida selvagem (Ohlendorf 1989, Skorupa 1998), um ecologista (Maier et al. 1987), um químico (Presser 1994, Presser et al. 1994), um modelador (Bowie et al. 1996), um especialista em selênio (Lemly 1999a) e outros especialistas (Davis et al. 1988, Sorensen 1991, Hamilton 1998). E todos concordam que a bioacumulação e os efeitos tóxicos do selênio em peixes e animais marinhos resultam primariamente da transferência via cadeia alimentar.

Segundo Hodson (1988), a toxicidade do selênio está ligada ao seu metabolismo pela biota aquática. Estudos comprovaram que existe uma diferença de metabolismo entre o selênio absorvido diretamente da água e o ingerido via dieta, sendo o último mais tóxico. Hodson \& Hilton (1983) propuseram modelos diferentes para estes em que o selênio absorvido pelas brânquias, diretamente da água, circularia através da maioria dos tecidos do peixe antes de chegar ao fígado, tornando-se disponível para a maioria dos tecidos. Enquanto o selênio, incorporado via dieta, passaria todo pelo fígado após absorção intestinal e teria uma ampla acumulação neste órgão, causando então, a toxicidade.

A maioria das descobertas importantes sobre o excesso de selênio na dieta foi realizada nas décadas de 30 e 40 e, estas tiveram um papel significante na condução de estudos sobre os organismos marinhos nas décadas de 80 e 90 (Ohlendorf 1999). Estes estudos revelaram que ao mesmo tempo em que o selênio é um nutriente, ele também pode tornar-se tóxico para os peixes em concentrações de 7 a 30 vezes aquela requerida em sua dieta $\left(>3 \mu \mathrm{g} . \mathrm{g}^{-1}\right)$ (Hodson \& Hilton 1983, Lemly 1997).

Segundo Lemly (1997), alguns dos principais efeitos tóxicos são devidos a um princípio da biologia celular, pois do ponto de vista bioquímico, o selênio é muito similar ao enxofre, não sendo, portanto, discriminado pelas células quando realizam suas funções - síntese de proteínas. Quando está presente em excesso, o selênio substitui erroneamente o enxofre nas proteínas que estão sendo formadas dentro das células. Ligações S-S (dissulfeto iônico) são necessárias para ordenar as moléculas de proteínas em sua estrutura terciária (hélice) que, é necessária para promover o funcionamento da proteína. A substituição do enxofre pelo selênio resulta na inativação de proteínas ou enzimas. 
Deformidades teratogênicas em peixes podem ser sinais patológicos de toxicidade por selênio. São malformações congênitas que ocorrem devido ao excesso de selênio nos ovos. O processo iniciase com a dieta dos peixes-pais. Excessos de selênio na dieta $\left(>3 \mu \mathrm{g} \cdot \mathrm{g}^{-1}\right)$ causam elevadas concentrações de selênio depositadas no desenvolvimento dos ovos, particularmente na gema. Esta gema contaminada será utilizada pelas larvas dos peixes que na sua formação terão deformidades devido à substituição do enxofre pelo selênio na formação de suas proteínas. A deformidade teratogênica pode ocorrer na maior parte, senão em todos os tecidos do corpo. Entretanto, algumas das mais evidentes são encontradas no esqueleto, nadadeiras, cabeça e boca. Estas envolvem tipicamente: (1) lordose - curvatura côncava da região lombar da espinha; (2) escoliose - curvatura lateral da espinha; (3) cifose - curvatura convexa da espinha na região torácica; (4) perda ou deformidade das nadadeiras; (5) perda ou deformidade das brânquias ou fechamento das guelras; (6) cabeça moldada anormalmente; (7) perda ou deformidade dos olhos; e (8) deformidades da boca (Lemly 1993, Lemly 1997, Lemly 1999a).

Níveis tóxicos de selênio podem também causar anormalidades reprodutoras, anemia e retardamento do crescimento (Eisler 1985), e podem reduzir a sobrevivência de embriões expostos e finalmente conduzir ao declínio de populações de peixes (Saiki et al. $1992 \mathrm{a}, \mathrm{b}$ apud Burger et al. 2001). Os efeitos do selênio são mais severos a baixas temperaturas, quando causam mudanças hematológicas e danos nas brânquias, e por último, a morte (Lemly 1993a apud Burger et al. 2001). Uma concentração de 4 $\mu \mathrm{g} \cdot \mathrm{g}^{-1} \mathrm{em}$ peso seco é o limiar para a toxicidade do selênio envolvendo a falta de reprodutividade em alguns peixes (Lemly \& Smith 1987 apud Burger et al. 2001), embora peixes mais sensíveis mostrem efeitos de 1 a $2 \mu \mathrm{g} \cdot \mathrm{g}^{-1}$ (Hamilton et al. 1990 apud Burger et al. 2001). Níveis nos músculos de $2,6 \mu \mathrm{g} \cdot \mathrm{g}^{-1}$ em peso úmido $\left(8 \mu \mathrm{g} \cdot \mathrm{g}^{-1}\right.$ em peso seco) estão associados a efeitos adversos nos próprios peixes (Lemly 1993a apud Burger et al. 2001). Além disso, níveis de selênio de $1 \mu \mathrm{g} \cdot \mathrm{g}^{-1}$ em peso úmido $\left(5 \mu \mathrm{g} \cdot \mathrm{g}^{-1}\right.$ em peso seco) são tóxicos para outros peixes e seus consumidores (Lemly 1993a apud Burger et al. 2001).

\section{CONCLUSÃO}

$\mathrm{O}$ estudo do selênio no ambiente é de extrema relevância, principalmente, devido à sua grande importância fisiológica e toxicológica. Porém, muito pouco se sabe a respeito deste elemento em regiões costeiras tropicais, como, por exemplo, a brasileira. Por isso, muito ainda tem que se estudar para se entender o comportamento do selênio nos organismos e no ambiente desta região.

\section{REFERÊNCIAS}

ALLANDER, E. 1994. Kashin-Beck disease: an analysis of research and public health activities based on a bibliography. Scandinavian Journal of Rheumatolology, 23:1849-1992.

AMWEG, E.L.; STUART, D.L. \& WESTON, D.P. 2003. Comparative bioavailability of selenium to aquatic organisms after treatment of agricultural drainage water. Aquatic Toxicology, 63:13-25.

AONO,T.; NAKAGUCHI, Y. \& HIRAKI, K. 1991. Vertical profiles of dissolved selenium in the North Pacific. Geochemical Journal, 25:45-55.

BARCELOUX, G. D. 1999. Selenium. Clinical Toxicology, 37(2):145-172.

BARGHIGIANI, G.; PELlEGRINI, D.; D’Ulivo, A. \& RANIERI, S. 1991. Mercury assessment and its relation to selenium levels in edible species of northern Tyrrhenian Sea. Marine Pollution Bulletin, 22:406-409.

BESSER, J.M.; GIESY, J.P.; BROWN, R.W.; BUELL, J.M. \& DAWSON, G.A. 1996. Selenium Bioaccumulation and Hazards in a Fish Community Affected by Coal Fly Ash Effluent. Ecotoxicology and Environmental Safety, $35: 7-15$.

BOTTINO, N.R.; BANKS, C.H.; IRGOLIC, K.J.; MICKS, P.; WHEELER, A.E. \& ZINGARO, R.A. 1984. Selenium containing amino acids and proteins in marine algae. Phytochemistry, 23:2445-2452.

BOWIE, G.L.; SANDRES, J.G.; RIEDEL, G.F.; GILMOUR, C.C.; BREITBURG, D.L.; CUTTER, G.A.; PORCELLA, D.B. 1996. Assessing selenium cycling and accumulation in aquatic ecosystems. Water, Air, and Soil Pollution, 90:93-104.

BOWIE, G.; PARALKAR, A.; PORCELLA, D.; CARLTON, R.; SANDERS, J.; RIEDEL, G.; GILMORE, C.; BREITBURG, D.; GOULDEN, C.; SANDERS, R.; OSMAN, R. \& CUTTER, G. 1998. Selenium. Modeling Selenium in 
Aquatic Ecosystems. Disponível em: http://www.epa.gov/ost/ selenium/report.html.

BURGER, J.; GAINES, K.F.; BORING, C.S.; STEPHENS, W.L.Jr.; SNODGRASS, J. \& GOCHFELD, M. 2001. Mercury and Selenium in Fish from the Savannah River: Species, Trophic Level, and Locational Differences. Environmental Research, Section A, 87:108-118.

BRADDON-GALLOWAY, S. \& SUMPTER, C.R. 1986. A unique selenoprotein isolated from yellowfin tuna (Thunnus albacares) liver. Comparative Biochemistry and Physiology, Part C, 83:13-17.

CARDELliCCHIO, N.; DECATALDO, A.; DI LEO, A. \& MISINO, A. 2002. Accumulation and Tissue Distribution of Mercury and Selenium in Striped Dolphins (Stenalla coeruleoalba) from the Mediterranean Sea (Southern Italy). Environmental Pollution, 116:265-271

CHAPMAN, P.M. 1999. Selenium - A potential time bomb or just another contaminant? Human and Ecological Risk Assessment, 5(6): 1123-1138.

CHATTERJEE, A.; BHATTACHARYA, B. \& DAS, R. 2001 Temporal and organ-specific variability of selenium in marine organisms from the eastern coast of India. Advances in Environmental Research, 5: 167-174.

CHEN, X.; YANG, G.; CHEN, J. 1980. Studies on the relations of selenium and Keshan disease. Biological Trace Element Research, 2:91-107.

CHEN, M.H.; SHIH, C.C.; CHOU, C.L. \& CHOU, L.S. 2002. Mercury, Organic Mercury and Selenium in Small Cetaceans in Taiwanese Waters. Marine Pollution Bulletin, $45: 237-245$.

COOKE, T.D. \& BRULAND, K.W. 1987. Aquatic chemistry of selenium: evidence of biomethylation. Environmental Science and Technology, 21:1214-1219.

CUTTER, G.A. 1982. Selenium in reducing waters. Science, 217:829-831

CUVIN, M.L.A. \& FURNESS, R.W. 1998. Uptake and Elimination of Inorganic Mercury and Selenium by minnows Phoxinus phoxinus. Aquatic Toxicology, 13:205-216.

DAVIS, E.A.; MAIER, K.J. \& KNIGHT, A.W. 1988. The biological consequences of selenium in aquatic ecosystems. California Agriculture, 42(1):18-20,29.

DIETZ, R.; RIGET, F. \& BORN, E.W. 2000. An assessment of selenium to mercury in Greenland marine animals. Science of the Total Environment, 245:15-24.

EISLER, R. 1985. Selenium hazards to fish, wildlife and invertebrates: a synoptic review. U.S. Fish and Wildlife Service Biological Report, 85, 1.5: 57.

ENDO, T.; HARAGUCHI, K. \& SAKATA, M. 2002. Mercury and selenium concentrations in the internal organs of toothed whales and dolphins marketed for human consumption in Japan. Science of the Total Environment, 300:15-22.

EPA 1998. Report on the peer consultation workshop on selenium aquatic toxicity and bioaccumulation. Office of water, U.S. Environmental Protection Agency, Washington D.C., USA.

FEROCI, G.; FINI, A.; BADIELLO, R. \& BRECCIA, A. 1997. Interaction between Selenium Derivatives and Heavy Metal Ions: $\mathrm{Cu}^{2+}$ and $\mathrm{Pb}^{2+}$. Microchemical Journal, 57:379-388.

FOSTER, L.H. \& SUMAR, S. 1997. Selenium in health and disease: a review. Critical Reviews in Food Science and Nutrition, 37: 211-228

FOWLER, S.W. \& BENAYOUN, G. 1976. Accumulation and distribution of selenium in mussel and shrimp tissues. Bulletin of Environmental Contamination and Toxicology, 16:339-346

FRANCESCONI, K.A.; GAILER, J.; EDMONDS, J.S.; GOESSLER, W. \& IRGOLIC, K.J. 1999. Uptake of ArsenicBetaines by the Mussel Mytilus edulis. Comparative Biochemistry and Physiology Part C, 122(1): 131-137.

GAILER J.; GEORGE G.M.; PICKERING I.J.; PRINCE R.C.; RINGWALD S.C.; PEMBERTON J.E.; GLASS R.S.; YOUNIS H.S.; DEYOUNG J.E. \& APOSHIAN H.V. 2000. A metabolic link between arsenite and selenite: The selenobis(S-glutathionyl)arsinium ion. Journal of the American Chemical Society, 122:4637-4639.

GENNITY,J.M.;BOTTINO, N.R.;ZINGARO, R.A.;WHEELER, A.E. \& IRGOLIC, K.J. 1984. The binding of selenium to the lipids of two unicellular marine algae. Biochemical and Biophysical Research Communications, 118:176-182.

HAMILTON, S.J. 1998. Selenium effects on endangered fish in the Colorado River basin. Pp 297-313. In: Jr.W.T. Frankenberger, R.A. Engberg, (eds.), Environmental chemistry of selenium. Marcel Dekker, New York.

HAMILTON, S.J. 2004. Review of selenium toxicity in the aquatic food chain. Science of the Total Environment, 326: 1-31.

HODSON, P.V. \& HILTON, J.W. 1983. The nutritional requirements and toxicity to fish of dietary and waterborne selenium. Ecological Bulletins, 35:335-340.

HODSON, P.V. 1988. The Effect of Metal Metabolism on Uptake, Disposition and Toxicity in Fish. Aquatic Toxicology, 11:3-18

HOLBEN, D.H. \& SMITH, A.M. 1999. The diverse role of selenium within selenoproteins: a review. Journal of the American Dietetic Association, 99(7): 836-43.

JONNALAGADDA, S.B. \& RAO, P.V.V.P. 1993. Toxicity, 
Bioavailability and Metal Speciation. Comparative Biochemistry and Physiology, 106C(3): 585-595.

KEHRIG, H.A.; SEIXAS, T.G.; BRITO-JR., J.L.; BAETA, A.P.; MOREIRA, I. \& MALM, O. 2004a. Relation between mercury, monomethylmercury and selenium in the muscle of coastal Brazilian fishes, $R M Z-M \& G, 51(1)$ : 1107-1110.

KEHRIG, H.A.; SEIXAS, T.G.; BAETA, A.P.; BRITO-JR., J.L.; MOREIRA, I. \& MALM, O. 2004b. Total mercury, methylmercury and selenium in the livers and muscle of different fishes and a marine mammal from a tropical estuary-Brazil. RMZ-Materials \& Geoenvironment, 51(1): 1111-1114.

KEHRIG, H.A.; SEIXAS, T.G.; MOREIRA, I. \& MALM, O. 2006. Bioacumulação de metais pesados e metalóides por bivalvos. In : Livro de resumos do III Encontro Nacional de Química Ambiental, Cabo Frio, Rio de Jeniro, Brasi, Pp. : 112.

KEHRIG, H.A.; SEIXAS, T.G.; FILLMANN, G. \& MALM, O. 2007a. Trace elements and methylmercury in tissues of magellanic penguins (Spheniscus magellanicus - Forster, 1781). Livro de resumos do SETAC Europe $17^{\text {th }}$ Annual Meeting, Porto, Portugal, Pp.: 206.

KEHRIG, H.A.; SEIXAS, T.G.; PALERMO, E.A. ; BAETA, A.P. ; CASTELO-BRANCO, C.W. ; MALM, O. \& MOREIRA, I. 2007b. The relationships between mercury and selenium in plankton and fishes along a tropical food web, submetido a Environmental Science Pollution Research.

KÖLBL, G. 1995. Concepts for the identification and determination of selenium compounds in the aquatic environment. Marine Chemistry, 48:185-197.

KUBOTA, R.; KUNITO, T. \& TANABE, S. 2002. Chemical speciation of arsenic in the livers of higher trophic marine animals. Marine Pollution Bulletin, 45:218-223.

LEMLY, A.D. 1993. Teratogenic Effects of Selenium in Natural Populations of Freshwater Fish. Ecotoxicology and Environmental Safety, 26:181-204.

LEMLY,A.D. 1997.ATeratogenic Deformity Index for Evaluating Impacts of selenium on Fish Populations. Ecotoxicology and Environmental Safety, 37:259-266.

LEMLY, A.D. 1999a. Selenium Impacts on Fish: An Insidious Time Bomb. Human and Ecological Risk Assessment, 5(6): 1139-1151.

LEMLY, A.D. 1999b. Selenium Transport and Bioaccumulation in Aquatic Ecosystems: A proposal for Water Quality Criteria Based on Hydrological Units. Ecotoxicology and Environmental Safety, 42:150-156.

LIU, D.L.; YANG, Y.P.; HU, M.H.; HARRISON, P.J. \& PRICE,
N.M. 1987. Selenium content of marine food chain organism from the coast of China. Marine Environmental Research, 22:151-165.

LUTEN, J.B.; BOUQUET, W.; BURGGRAF, M.M. \& RUS, J. 1987. The in-vitro availability of copper, zinc and selenium and the speciation of selenium in fishery products. Pp 509-519. In: P. Brätter and P. Schramel, (eds), Trace Element-Analytical Chemistry in Medicine and Biology. De Gruyter, Berlin.

MAIER, K.J.; FOE, C.; OGLE, R.S., WILLIAMS, M.J.; KNIGHT, A.W., KIFFNEY, P. \& MELTON, L.A. 1987. The dynamics of selenium in aquatic ecosystems. Trace Substances in Environmental Health, 21:361-408.

MATSUMOTO, K. 1991. Speciation and determination of Selenium and Mercury Accumulated in a Dolphin Liver. ACS Symposium Series, 445:278-289.

MCNEAL, J.M. \& BALISTRIERI, L.S. 1989. Geochemistry and occurrence of selenium: Na overview. Pp 1-13. In: L.W. Jacobs, (ed.), SSSA Spec. Publ., 23. Selenium Agric. Environ., Madison, WI.

NAS 1976. Selenium, National Academy of Sciences, Washington D.C.

OHLENDORF, H.M. 1999. Selenium Was a Time Bomb. Human and Ecological Risk Assessment, 5(6):1181-1185.

OLIVAS, R.M.; DONARD, O.F.X.; CÁMARA, C. \& QUEVAUVILlER, P. 1994. Analytical techniques applied to the speciation of selenium in environmental matrices. Analytica Chimica Acta, 286:357-370.

OMS 1987. Selenium. Environmental Health Criteria $N^{\circ} 58$. World Health Organization, Geneva, Switzerland.

OYAMADA, N. \& ISHIZAKI, M. 1986. Fractional determination of dissolved selenium compounds of trimethylselenonium íon, selenium (IV) and selenium (VI) in environmental water samples. Analytical Sciences, 2:365-369.

OYAMADA, N.; TAKAHASHI, G. \& ISHIZAKI, M. 1991. Methylation of inorganic selenium compounds by freshwater green algae, Ankistrodesmus sp., Chlorella vulgaris and Selenastrum sp. Eisei Kagaku, 37:83-88.

PALMISANO F, CARDELLICCHIO N, ZAMBONIN PG. 1995. Speciation of mercury in dolphin liver: a two-stage mechanism for the demethylation accumulation process and role of selenium. Marine Environmental Research, 40: 109-1218

PELLETIER, E. 1985. Mercury-selenium interactions in aquatic organisms: a review. Marine Environment Research, 18:111-132.

PING, L.; NAGASAWA, H.; MATSUMOTO, K.; SUZUKI, A. \& FUWA, K. 1986. Extraction and purification of a new 
compound containing selenium and mercury accumulated in dolphin liver. Biological Trace Element Research, 11:185-199.

PRESSER, T.S. 1994. The Kesterson effect. Environmental Manage, 18:437-454.

PRESSER, T.S.; SYLVESTER, M.A. \& LOW, W.H. 1994. Bioaccumulation of selenium from natural geologic sources in Western states and its potential consequences. Environmental Manage, 18:423-436.

PURKERSON,D.G.;DOBLIN,M.A.;BOLLENS,S.M.;LUOMA, S.N.; CUTTER, G.A. 2003. Selenium in San Francisco Bay Zooplankton: Potential Effects of hydrodynamics and food web interactions. Estuaries, 26(4A): 956-969.

RAND, G.M.; WELLS, P.G.; MCCARTHY, L.S. 1995. Introduction to aquatic ecology. Pp 3-53. In: G.M. Rand, (ed.), Fundamentals of Aquatic Toxicology. Taylor and Francis, London.

SAIKI, M.K. 1986. A field example of selenium contamination in an aquatic food chain. Pp 67-76. In: Selenium in the Environment, Publication Number CAT1/860201, California agricultural Technology Institute, California State University, Fresno.

SASAKURA, C. \& SUZUKI, K. 1998. Biological interaction between transition metals $(\mathrm{Ag}, \mathrm{Cd}$ and $\mathrm{Hg}$ ) selenite/sulfide and selenoprotein P. Journal of Inorganic Biochemistry, 71:159-162.

SATO, T., OSE, Y. \& SAKAI, T. 1980. Toxicological effect of selenium on fish. Environmental Pollution, 21A:217-224.

SCHULTZ, A.; SKARPING, G.; SKERFVING, S.; MALMQUIST, K. 1994. Mercury. Pp 403-446. In: R.F.M. Herber, M. Stoeppler, (eds.), Trace element analysis in biological specimens. Elsevier, London, Amsterdam, New York and Tokyo.

SCHWARZ, K. \& FOLTZ, C.M. 1957. Selenium as an integral part of factor 3 against dietary necrotic liver degeneration. Journal of the American Chemistry Society, 79: 32923293.

SEIXAS, T.G., KEHRIG, H.A., MOREIRA, I. \& MALM, O., 2007a. Distribuição de Selênio em organismos marinhos da Baía de Guanabara/ R.J. Química Nova, 30(3): 554-559.

SEIXAS, T.G., KEHRIG, H.A., FILLMANN, G.; DI BENEDITTO, A.P.M.; SOUZA, C.M.M.; SECCHI, E.R.; MOREIRA, I. \& MALM, O., 2007b. Ecological and biological determinants of trace elements accumulation in liver and kidney of Pontoporia blainvillei. Science of the Total Environment, 385(1-3):208-220.

SHIBATA, Y., MORITA, M., FUWA, K., 1992. Selenium and arsenic in biology: their chemical forms and biological functions. Advances in Biophysics, 28:31-80.

SKORUPA, J.P. 1998. Selenium poisoning of fish and wildlife in nature: lessons from twelve real-world examples. Pp 315-354. In: Jr.W.T. Frankenberger, R.A. Engberg, (eds.), Environmental chemistry of selenium. New York.

SORENSEN, M. \& BJERREGAARD, P. 1991. Interactive accumulation of mercury and selenium in the sea star Asterias rubens. Marine Biology, 108:269-276.

STADTMAN, T. C. 1974. Selenium biochemistry. Science, 183:915-921.

STADTMAN, T. C. 1977. Biological function of selenium. Nutrition Reviews, 35:161-166.

TAKEMATSU, N.; SATO, Y.; OKABE, S. \& USUI, A. 1990. Uptake of selenium and other oxoanionic elements in marine ferro-manganese concretions of different origin. Marine Chemistry, 31:271-283.

TAMARI, Y. 1979. Neutron activation analysis of selenium and 17 elements in sediment. Radioisotopes, 28:1-6.

TANZER, D. \& HEUMANN, K.G. 1990. GC determination of dimethyl selenide and trimethyl selenonium ions in aquatic systems using element specific detection. Atmospheric Environment A, 24:3099-3102.

TANZER, D. \& HEUMANN, K.G. 1992. Gas chromatographic trace-level determonation of volatile organic sulfides and selenides and of methyl iodide in Atlantic surface water. International Journal of Environmental Analytical Chemistry, 48:17-31.

THOMPSON, J.M. \& SCOTT, M.L. 1969. Role of Selenium in the Nutrition of The Chick. The Journal of Nutrition, 97: 335-342.

THOMPSON-EAGLE， E.T. \& FRANKENBERGER JR., W.T. 1990. Protein-mediated selenium biomethylation in evaporation pond water. Environmental Toxicology and Chemistry, 9:1453-1462.

VIDAL, M.F.C. 1984. Determinação de Selênio em Material Biológico por Espectrofotometria de Absorção Atômica no Forno de Grafite e por Geração de Vapor. Dissertação de mestrado apresentada ao Departamento de Química da PUC-RJ.

WACHOWICZ, B. ZBIKOWSKA, H.A. \& NOWAK, P. 2001. Selenium compounds in the environment: their effect on human health. Cellular and Molecular Biology Letters, 6(2a): 375-381.

WAGEMANN, R.; TREBACZ, E.; BOILA, G. \& LOCKHART, W.L. 1998. Methylmercury and total mercury in tissues of arctic marine mammals. Science of the Total Environment, 218:19-31. 
WAGEMANN, R.; TREBACS, E.; BOILA, G. \& LOCKHART, W.L. 2000. Mercury species in the liver of ringed seals. Science of the Total Environment, 261: 21-32.

WATANABE, T.; KIRON, V. \& SATOH, S. 1997. Trace Minerals in Fish Nutrition. Aquaculture, 151:185-207.

WRENCH, J.J. 1978. Selenium matabolism in marine phytoplankters Tetraselmis tetrathele and Dunaliella minuta. Marine Biology, 49:231-236.

WRENCH, J.J. \& MEASURES, C.I. 1979. Uptake and metabolism of selenium by oysters. Marine Science Communications, 5:47-59.

XU, G-L; WANG, S-C; GU, B-Q. 1997. Further investigation of the role of selenium deficiency in the aetiology and pathogenesis of Keshan disease. Biomedical and Environmental Sciences, 10: $316-326$. 